\title{
Blends of Agar/Galactomannan for Marubakaido Apple Rootstock Shoot Proliferation
}

\author{
N. Lucyszyn \\ Departamento de Botânica, Departamento de Química, UFPR \\ M. Quoirin \\ Departamento de Botânica, UFPR
}

A. Anjos

Departamento de Estatística, UFPR

\author{
M.-R. Sierakowski \\ Departamento de Química, UFPR
}

\begin{abstract}
Galactomannans (GMs) extracted from seeds of a native Brazilian specie designated Cassia fastuosa (cassia) and from Cyamopsis tetragonolobus (guar gum - a commercial GM) were mixed with agar, in the proportion of $3 / 3$ g.L. ${ }^{-1}$ $(\mathrm{w} / \mathrm{w})$, and used as a gelling agent in Marubakaido apple rootstock (Malus prunifolia Borkh) micropropagation. The rheological measurements of the gels showed a good interaction between both hidrocolloids. The micropropagation results on these media were compared with behaviour of standard medium containing agar only ( 6 g.L.L $\left.\mathrm{L}^{-1}\right)$. Results from in vitro experiments indicated enhanced proliferation of apple shoots and also the occurrence of hyperhydric shoots was lower in the modified gel-medium.
\end{abstract}

Keywords: Galactomannan, micropropagation, apple tree, gelled medium.

Introduction

Micropropagation techniques have been developed for a number of fruit species as a means of rapid clonal propagation ${ }^{[1]}$. Maximising shoot proliferation is a basic objective of micropropagation and much attention has been focused on a gelling agent used in the culture medium. Most culture media are solidified with agar, a family of polysaccharides obtained from some families of red macro algae (Rhodophyta), mainly Graciliaceae and Gelidiaceae. The structure of agar consists of alternated $\beta-1,3$, and $\alpha-1,4$ linked $\mathrm{D}$ and $\mathrm{L}$ galactose residues, respectively ${ }^{[2]}$. The polysaccharide is an expensive ingredient and it is well known that it can have an effect on the growth and development of in vitro cultures ${ }^{[3]}$. The reaction of the plant to the agar-type or brand is strongly dependent on the culture process and on the plant species ${ }^{[4]}$. A general problem related to agar-type is hyperhydricity and necrosis of tissue ${ }^{[5]}$. Different explanations have been proposed to justify the influence of agar-induced variations in vitro. These include the presence of inhibitors in agar ${ }^{[6]}$, the effect of agar on the rate of molecule diffusion through the medium ${ }^{[7]}$, variations in the availability of water ${ }^{[8]}$ and differences in gel strength and mineral composition ${ }^{[3]}$. Due to these reasons and the high price of tissue culture grade agar, attempts have been made to identify suitable alternatives. A wide range of substances, viz. Carrageenans ${ }^{[9]}$, Gelrite ${ }^{[5]}$, sago and isubgo ${ }^{[10]}$, and xyloglucan ${ }^{[11]}$, have been tried as substitute or partial substitute for agar.

Other polymers, such as galactomannans (GMs), also occur in large amounts in plant seeds. They essentially consist of 1-4 linked $\beta$-D-mannopyranosyl backbone partially substituted at O-6 with D-galactopyranosyl side groups ${ }^{[12]}$. Two GMs are produced commercially in great amounts: guar gum from Cyamopsis tetragonolobus and locust bean gum from carob (Ceratonia siliqua) $)^{[13]}$. The first has a polysaccharide structure characterized by Man/ Gal ratio near to 2:1 and the second near to 4:1. To compete with the great demand for gums, a native tree of Brazil has been investigated for GM production. Cassia fastuosa, a Caesalpiniaceae, also known as Cassia, Maripixuma, Parica, contains a legume with 40-50 seeds with total mass of 8$10 \mathrm{~g}$, and from which seeds the GM used in this work was extracted.

To evaluate the physical properties of agar/ galactomannan mixture in the culture media rheological techniques and diffusion tests were applied. The viscoelastic behaviour of polysaccharide blends in the media was compared with the individual components, using oscillatory measurements. Furthermore, was investigated the in vitro effect of partial substitution of agar by galactomannans from

Autor para correspondência: Maria Rita Sierakowski, Departamento de Química, UFPR, Caixa Postal 19081, CEP: 81531-990, Curitiba, PR. E-mail mariarita.sierakowski@ufpr.br 
guar and cassia seeds in Marubakaido apple rootstock micropropagation.

\section{Materials and Methods}

\section{Polysaccharide commercial sources}

Commercial guar galactomannan from seeds of Cyamopsis tetragonolobus (Indian Gum Industries Limited - B-5/7. M.I.A., Basni, Phase - Ist, Jodhpur-342005, India) was kindly provided by Herbarium S.A. - Produtos Naturais - Curitiba/ Brazil, and Agar was imported (Merck $1615^{\circledR}$ - Germany).

\section{Cassia Galactomannan extraction}

Cassia fastuosa seeds (50g) collected in Curitiba, Paraná State (Brazil) were boiled in water for $20 \mathrm{~min}$ in order to inactivate the enzymes. The milled seeds were successively extracted (five times) with water at $25^{\circ} \mathrm{C}$, and the residue was removed by centrifugation for $40 \mathrm{~min}$ at $7000 \mathrm{rpm}$. The combined supernatants were evaporated at $40{ }^{\circ} \mathrm{C}$ and reduced to a small volume. $\mathrm{NaCl}$ was added into the solution in order to obtain a concentration of $0.1 \mathrm{M}$ and the polysaccharide was precipitated with 2 volumes of commercial ethanol. The galactomannan obtained was filtered through cloth and dried at $25{ }^{\circ} \mathrm{C}$.

\section{Chemical analysis of the galactomannan samples}

Total carbohydrate was estimated by phenol-sulfuric acid method ${ }^{[14]}$. Protein content was determined according to the method of Hartree (1972) $)^{[15]}$.

Total acid hydrolysis was performed with $1 \mathrm{M}$ trifluoracetic acid at $100^{\circ} \mathrm{C}$ for $5 \mathrm{~h}$ and the liberated monosaccharides converted into alditol acetates ${ }^{[16]}$. Gas-liquid chromatography (GLC) was performed at $220^{\circ} \mathrm{C}$ with J \& W DB 225 column $(0.25-\mathrm{mm}$ i.d. $\times 30 \mathrm{~m})$ with nitrogen as carrier gas $\left(2 \mathrm{~mL} \cdot \mathrm{min}^{-1}\right)$, in a HP 5890 SII chromatograph.

Molecular weight (Mw) was established through highperformance size exclusion chromatography (HPSEC), coupled with a differential refractometer, and a multi-angle laser light scattering (MALLS) in a WYATT technology light scattering system. To this analysis firstly the GMs solutions were filtered at 0.45 and $0.22 \mu \mathrm{m}$ pore Millipore membranes and injected into a GPC having in serie 2000, 500, 250 and 120 ultragel columns. The eluent was $0.1 \mathrm{M} \mathrm{NaNO}{ }_{2}-0.02 \%$ $\mathrm{NaN}_{3}$ solution, with a controlled flow of $0.6 \mathrm{~mL} \cdot \mathrm{min}^{-1}$.

\section{Rheological measurements}

Oscillatory tests, at $25^{\circ} \mathrm{C}$, were done in the frequency of $0.05-10 \mathrm{~Hz}$, deformation of $0.35-0.60 \%$ (viscoelastic region) of the media gelled with agar or agar/galactomannan mixture, using a Haake Rheometer (RS75), equipped with a C60/2 sensor and Haake software.

\section{Diffusion tests}

To verify the influence of the gels on diffusion process of components in the culture media a methylene blue solution $\left(0.5 \mathrm{~g} . \mathrm{L}^{-1}\right.$ in water) was applying $(50 \mu \mathrm{L})$ on the top of column medium $(5 \mathrm{~mL})$ formed in conic graduate tubes $(12 \mathrm{~mL})$. The penetration of colouring was analysed at $25^{\circ} \mathrm{C}$, by visual observation on the scale, after 24, 48, 72 and 120 h. Each treatment contained 3 replicates.

\section{Plant material}

Shoots from Marubakaido apple rootstock (Malus prunifolia Borkh) were provided by EMBRAPA (Empresa Brasileira de Pesquisa Agropecuária), Pelotas-RS-Brazil.

\section{Gelling agents and medium preparation}

The effect of the gelling agent on the in vitro performance was studied by culturing the shoots on a standard medium gelled with agar $\left(6 \mathrm{~g} . \mathrm{L}^{-1}\right)$, or on a blend created by a mixture of agar/ galactomannan ( 3 g.L $\mathrm{L}^{-1}$ each). For the preparation of modified media, galactomannans were dissolved in distilled water by stirring at $25^{\circ} \mathrm{C}$ overnight and, then, were added to MS liquid medium. The $\mathrm{pH}$ of all media was adjusted to 5.8 with aqueous $\mathrm{NaOH}$ or $\mathrm{HCl}$ solution. The medium containing 6 g. $\mathrm{L}^{-1}$ of agar or galactomannan was heated separately in a microwave and then mixed $\left(3 / 3 \mathrm{~g} . \mathrm{L}^{-1}, \mathrm{w} / \mathrm{w}\right)$. The media solutions were poured into glass flasks ( $60 \mathrm{~mm} \varnothing \times 80 \mathrm{~mm}$ high), each one containing $30 \mathrm{~mL}$ of medium and covered with aluminium foil. The samples were autoclaved for $20 \mathrm{~min}$ at $121^{\circ} \mathrm{C}$ and $1.2 \mathrm{~kg} / \mathrm{cm}^{-2}$, after this were cooled and stored at $25^{\circ} \mathrm{C}$.

\section{Tissue culture experiments}

Shoots from previously established cultures of apple rootstock Marubakaido (Malus prunifolia Borkh) were grown on a basal medium denominated Murashige and Skoog (1962) which consisted of salts and vitamins ${ }^{[17]}$, sucrose $\left(30\right.$ g.L L $\left.^{-1}\right)$, supplemented with $2.22 \mu \mathrm{M}$ or $4.44 \mu \mathrm{M}$ BA, in factorial combination with gelling agents. Six shoot segments $( \pm 1 \mathrm{~cm}$ long) with four to six leaves were used per culture flask. All treatments consisted of 10 replications. After 40 days on multiplication media, shoot multiplication was evaluated by counting the number of shoots per explant. The shoot length was measured and the hyperhydricity, based on visual observations, was estimated by scoring the percentage of hyperhydric shoots. Cultures were maintained in a growth chamber at $25 \pm 2{ }^{\circ} \mathrm{C}$ under "daylight" fluorescent tubes providing an irradiance of $40 \mu \mathrm{mol} \cdot \mathrm{m}^{-2} \cdot \mathrm{s}^{-1}$ and a $16 \mathrm{~h}$ photoperiod. Treatment means were compared by Tukey's test in the MSTAT program (Michigan State University), version 2.11. Significance was recorded at $\mathrm{p}<0.05$.

\section{Results and Discussion}

\section{Polysaccharides Analysis}

Milled seeds from Cassia fastuosa by aqueous extraction yielded $37 \%(\mathrm{w} / \mathrm{w})$ of galactomannan (based on whole seeds). For Cyamopsis tetragonolobus and Cassia fastuosa galactomannans, the molecular weight was, respectively, 675,100 and 462,600 g.mol ${ }^{-1}$, the protein content was 10 and $11 \%$; the total carbohydrate was 85 and $82 \%$, and the mannose:galactose ratios was 1.9:1 and 3.0:1. So, the cassia 

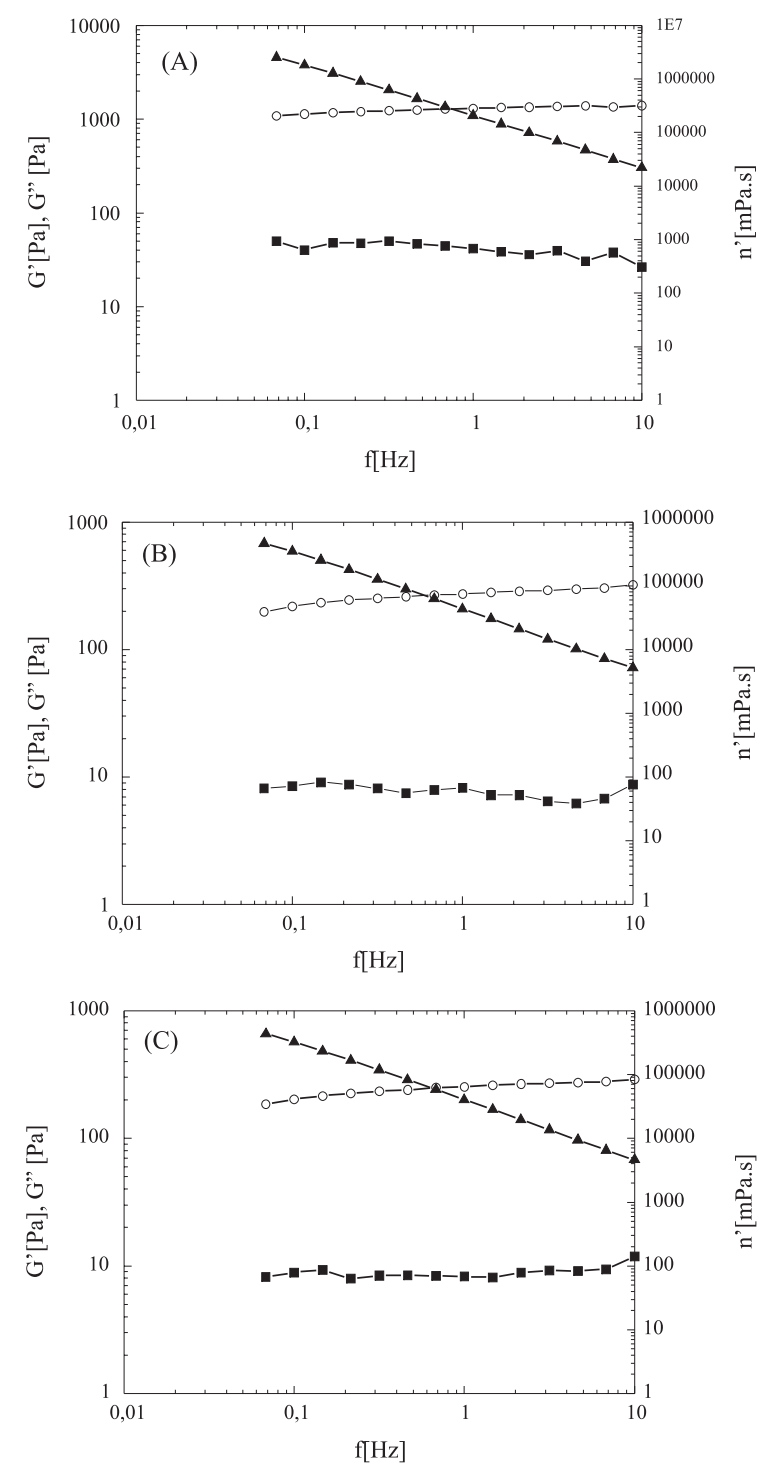

Figure 1. Dynamic viscosity, $\eta^{\prime}(\mathbf{\Delta})$, storage modulus, G' (O), and loss modulus, G" (ם), versus frequency for agar (A), 6 g. $\mathrm{L}^{-1}$; agar/cassia galactomannan - blend (B), (3/3 g.L $\left.\mathrm{L}^{-1}, \mathrm{w} / \mathrm{w}\right)$; agar/guar galactomannan blend (C), (3/3 g.L $\mathrm{L}^{-1}$, w/w) using Haake Rheometer RS75, with $\mathrm{C} 60 / 2^{\circ}$ sensor, at $25{ }^{\circ} \mathrm{C}$, equipped with Haake software.

GM is the lower substitute and in terms of chemical composition each sample corresponds to a proteoglycan.

\section{Rheological properties}

In order to analyse the linear viscoelastic properties of the modified media, rheological measurements were carried out in oscillatory systems and the results were compared to agar at $6 \mathrm{~g} / \mathrm{L}^{-1}$. In a dynamic test, for agar at $6 \mathrm{~g} . \mathrm{L}^{-1}$ (Figure $1 \mathrm{~A}$ ), the values of G' are between 22 to 53 times higher than those of G" in the interval of frequencies analysed. To the agar/ cassia galactomannan and agar/guar galactomannan mixtures at 3/3 g.L. $\mathrm{L}^{-1}$, w/w (Figure 1B, 1C, respectively) the values of G' are between 22 to 49 times higher than that of G', for all interval of frequencies measured. These results showed that agar and the mixtures have a solid character, expressed by the elastic modulus (G'), much more important than its

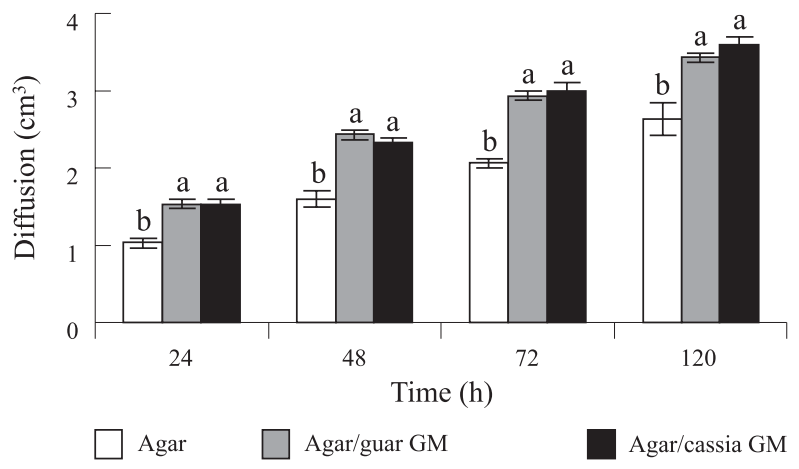

Figure 2. Diffusion of the methylene blue in the MS basal medium gelled with agar $\left(6\right.$ g.L.-1), agar/guar galactomannan - blend $\left(3 / 3\right.$ g.L $\left.\mathrm{L}^{-1}, \mathrm{w} / \mathrm{w}\right)$ or agar/cassia galactomannan - blend $\left(3 / 3\right.$ g. $\left.\mathrm{L}^{-1}, \mathrm{w} / \mathrm{w}\right)$. Each value is the mean of 3 replicates (means $\pm \mathrm{SD}$ ). Means followed by the same letter in the same period are not significantly different as indicated by the Tukey's test at $\mathrm{p}<0.05$.

behaviour as liquid, expressed by the viscous modulus (G”) indicating that true gels are formed. In all media, the dynamic viscosity $(\eta$ ') decreased linearly with increasing frequency of oscillations, which behaviour is typical of a strong gel ${ }^{[18]}$.

\section{Diffusion tests}

As observed in the results presented in the Figure 2, the diffusion of colouring methylene blue in the agar/guar and also in agar/cassia GM mixture has the same performance but a significant difference was observed in comparison to media gelled with agar only, in which the diffusion was slower. These results are in agreement with studies accomplished by Ackers and Steere (1962) ${ }^{[19]}$ that showed that the separation and the diffusion of a solute decreases with the increase of the size of the particles of this solute and/or with the increase in the gel strength. So, better diffusion of water and others components occurs in modified media formulated by agar/GM blends.

\section{Micropropagation experiments}

Shoot number and length were significantly affected by gelling agent $(\mathrm{P}=0.0143)$ but not by the interaction gelling agent and BA concentration ( $\mathrm{P}=0.7290)$, since the presence of BA at 2.22 and $4.44 \mu \mathrm{M}$ gave a similar response. The shoot number was enhanced by the agar/guar galactomannan blend when compared to the control with agar only, but no significant difference was observed. The length of shoots was higher in the agar-gelled medium, however not significant difference was observed in relation to the agar/guar galactomannan mixture. In the agar/cassia galactomannan blend the shoot number and shoot length were lower than on media gelled with agar or agar/guar galactomannan (Table 1, Figure 3).

By the results was observed that there was a significant interaction between gelling agent and BA concentration for hyperhydric shoots $(P=0.0000)$. For both concentrations of $\mathrm{BA}$, a significant reduction in the percentage of hyperhydric shoots was observed on the medium gelled with agar/ galactomannan mixtures. In the medium gelled with the agar/ cassia GM blend and containing $4.44 \mu \mathrm{MBA}$ the hyperhydricity was not observed (Table 2). 
Table 1. Effect of gelling agents on shoot number and length of Marubakaido apple rootstock in MS medium after six weeks of culture.

\begin{tabular}{ccc}
\hline Gelling agent & Shoot number & $\begin{array}{c}\text { Shoot length } \\
(\mathbf{c m})\end{array}$ \\
\hline Agar & $7.16 \pm 1.24 \mathrm{ab}$ & $1.85 \pm 0.25 \mathrm{a}$ \\
Agar/guar galactomannan & $7.60 \pm 1.45 \mathrm{a}$ & $1.81 \pm 0.21 \mathrm{a}$ \\
Agar/cassia galactomannan & $6.19 \pm 1.76 \mathrm{~b}$ & $1.17 \pm 0.25 \mathrm{~b}$ \\
\hline
\end{tabular}

Means of two independent experiments \pm SD. Means followed by the same letter are not significantly different as indicated by the Tukey's test at $\mathrm{p}<$ 0.05 .

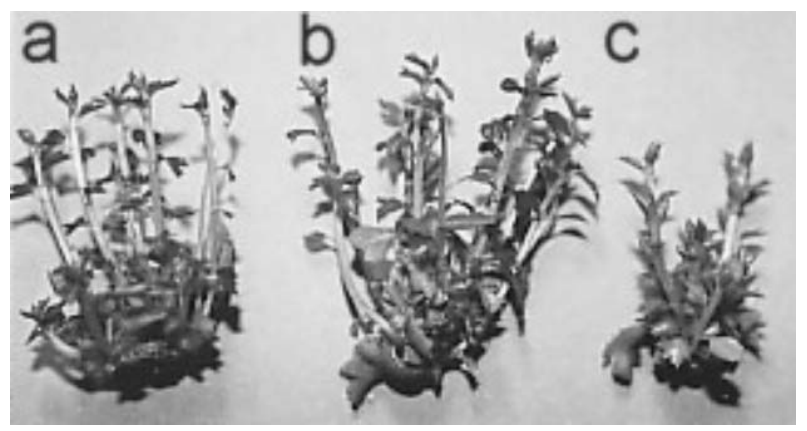

Figure 3. Shoot proliferation of Marubakaido apple rootstock cultured for 6 weeks on medium gelled with: (a) agar (6 g. $\left.\mathrm{L}^{-1}\right)$; (b) agar/guar galactomannan blend (3/3 g.L.- $\left.\mathrm{L}^{-1}, \mathrm{w} / \mathrm{w}\right)$; (c) agar/cassia galactomannan blend $\left(3 / 3\right.$ g.L $\left.{ }^{-1}, w / w\right)$.

Table 2. Effect of interaction between gelling agents and BA concentration on hyperhydric shoots of Marubakaido apple rootstock in MS medium after six weeks of culture.

\begin{tabular}{cccc}
\hline & & \multicolumn{2}{c}{ BA concentration $(\boldsymbol{\mu M})$} \\
Gelling agent & $\mathbf{2 . 2 2}$ & $\mathbf{4 . 4 4}$ \\
\hline $\begin{array}{c}\text { Hyperhydric } \\
\text { shoots } \\
(\%)\end{array}$ & $\begin{array}{c}\text { Agar } \\
\text { galactomannan } \\
\text { Agar/cassia } \\
\text { galactomannan }\end{array}$ & $2.50 \pm 0.88$ c & 0.00 \\
\hline
\end{tabular}

Means of two independent experiments \pm SD. Means followed by the same letter in the same concentration of BA are not significantly different as indicated by the Tukey's test at $\mathrm{p}<0.05$.

\section{Conclusions}

By rheological measurements it was observed that the media in which agar was partially substituted by galactomannans the strong gel characteristics was not lost. The resulting blends with different textural properties, softer than pure agar gels, may be preferable in plant tissue culture. Like this, for example, the agar/GM mixture may provide better diffusion of media components to the plant tissues, allowing for a better in vitro development.

With the results obtained is possible to conclude that an enhanced proliferation of shoots can be obtained when grown on a medium gelled with agar/galactomannan blends.
Improvement of the performance of micropropagation by using the mixture of agar and different alternative agents has already been described in the literature ${ }^{[11,20,21]}$. Zimmerman et al. $(1995)^{[21]}$ used the blend of starch and Gelrite ${ }^{\circledR}$ to propagate five apple and two pear cultivars. For apple, the proliferation was improved for four cultivars, but in the case of pear, shoot proliferation was significantly reduced due to higher hyperhydricity in the presence of two gelling agents, which was counteracted by adding a commercially hydric control agent in the media. Hyperhydricity phenomenon occurs frequently in solidified media with a higher concentration of gelling agent or a gelling agent with a higher gel strength ${ }^{[22]}$.

For Marubakaido apple rootstock, the multiplication of shoots was raised on media gelled with the agar/guar galactomannan blend, the presence of hyperhydric shoots was reduced in the modified media and not observed in explants cultured on the medium solidified with agar/cassia galactomannan containing $4.44 \mu \mathrm{M}$ BA. Thus, the chief problem of hyperhydricity, which in turn reduces or eliminates shoot proliferation, could be minimised utilising our modified systems.

The major advantage of the agar/galactomannan blends is the reduction of gelling agent cost in the micropropagation process. Thus, gels of a specific strength can be prepared with the mixture of agar/galactomannan and lower agar consumption would be required. The resulting gels, with different textural properties from those of the pure agar, may be preferable in plant tissue culture.

\section{Acknowledgements}

The authors thank EMBRAPA (Empresa Brasileira de Pesquisa Agropecuária, Pelotas-RS, Brazil) for Marubakaido apple rootstock plantlets; Herbarium S.A. - Produtos Naturais (Curitiba - PR, Brazil) for the donation of commercial guar galactomannan and the Brazilian funding agencies CAPES (Coordenação de Aperfeiçoamento de Pessoal de Nível Superior) and CNPq (Conselho Nacional de Pesquisa) for financial support.

\section{References}

1. Jain, S. M. \& Ishii, K. - "Micropropagation of woody trees and fruits", Kluwer Academic, London (2003).

2. Glicksman, M. - "Red Seaweed extracts (agar, carrageenans, and furcellaran)", in: Food Hydrocolloids 2, p. 73-113, Glicksman, M. (ed.), CRC Press, Boca Raton (1983).

3. Singha, S. J., - Am. Soc. Hort. Sci., 107(4), p. 657-660 (1982).

4. Scholten, H. J. \& Pierik, R. L. M. - Scientia Horticult., 77, p. 109-116 (1998).

5. Pasqualetto, P.-L.; Zimmerman, R. H. \& Fordhan, I. J. Plant Cell Tiss. Org. Cult., 14, p. 31-40 (1988). 
6. Kohlenbach, H. W. \& Wernicke, W. Z. - Pflanzenphysiol., 86, p. 463-472 (1978).

7. Romberger, J. Á. \& Tabor, C. A. - Am. J. Bot., 58, p. 131140 (1971).

8. Stolz, L. P. - J. Am. Hort. Science 96, p. 618-684 (1971).

9. Lines, A. D. - Appl. Environ. Microbiol., 34, p. 637-639 (1977).

10. Bhattacharya, P.; Dey, S. \& Bhattacharyya, B. C. - Plant Cell Tiss. Org. Cult., 37, p. 15-23 (1994).

11. Lima-Nishimura, N.; Quoirin, M.; Naddaf,Y. G.; Wilhelm, H. M.; Ribas, L. L. F. \& Sierakowski, M.-R. - Plant cell Rep., 21, p. 402-407 (2003).

12. Dea. I. C. M. \& Morrison, A. - Adv. Carbohydr. Chem. Biochem., 31, p. 241-312 (1975).

13. Maier, H.; Anderson, M.; Karl, C.; Maqnuson, K. \& Whistler, R. L. - "Guar, Locust Bean, Tara and Fenugreek Gums", in: Industrial Gums: Polysaccharides and Their Derivatives, p. 215-218, Whistler, R. L. \& Bemiller, J. N. (eds.), Academic Press, New York (1993).
14. Dubois, M.; Gilles, K. A.; Hamilton, J. K., Rebers, P. A. \& Smith, F. - Anal. Chem., 28, p. 350-356 (1956).

15. Hartree, E. F. - Anal. Biochem., 48, p. $422-427$ (1972).

16. Wolfrom, M. L \& Thompson, A. - "Acetylation". in: Methods in carbohydrate chemistry 2, p. 211-215, Whistler, R. L. (ed.), Academic Press, New York (1963).

17. Murashige, T. \& Skoog, F. - Physiol. Plant., 15, p. 473497 (1962).

18. Rees, D. A. - Adv. Carbohydr. Chem. Biochem., 24, p. 267-332 (1969).

19. Ackers, G. K. \& Steere, R. L. - Biochimica et Biophysica Acta, 59, p. 137-149 (1962).

20. Lucyszyn, N.; Sierakowski, M.-R. \& Quoirin, M. - "Use of agar-galactomannan gels for tobacco (Nicotiana tabacum) tissue culture", in: Proceedings of IV International Symposium on Natural Polymers and Composites, São Pedro - São Paulo, set (2002).

21. Zimmerman, R. H.; Bhardwaj, S. V. \& Fordham, I. M. Plant Cell Tiss. Org. Cult., 43, p. 207-213 (1995).

22. Debergh, P. C.; Harbaoui, Y. \& Lemeur, R. Phisiol. Plant., 53, p. 181-187 (1981). 